\title{
Short communication: Reactivity of diacetyl with cleaning and sanitizing agents
}

\author{
M. I. Rincon-Delgadillo, A. Lopez-Hernandez, and S. A. Rankin ${ }^{1}$ \\ Department of Food Science, University of Wisconsin-Madison, 1605 Linden Drive, Madison 53706
}

\begin{abstract}
Diacetyl is used to impart a buttery flavor to numerous food products such as sour cream, cottage cheese, vegetable oil-based spreads, baked goods, and beverages. Recent studies have linked exposure to high concentrations of diacetyl and the onset of bronchiolitis obliterans. Due to the reported risks that diacetyl may pose, many food companies have altered practices to reduce worker exposure to diacetyl, including the use of personal respirators, improved air handling systems, and adequate cleaning practices. Commonly used cleaning and sanitizing agents may be reactive with diacetyl; however, the efficacy of these chemicals has not been studied in detail and remains unclear. The objective of this work was to study the reaction chemistry of diacetyl with common industrial cleaning and sanitizing chemicals. The reactions were assessed at equimolar concentrations and analyzed by gas chromatography-mass spectrometry. Peroxyacetic acid was most reactive with diacetyl (95\% reduction in diacetyl), followed by sodium hypochlorite (76\% reduction), and hydrogen peroxide (26\% reduction). Benzalkonium chloride (BAC) did not react with diacetyl. Acetic acid was detected as the main product of reactions of diacetyl with peroxyacetic acid, sodium hypochlorite, and hydrogen peroxide. 1,1-Dichloro-2-propanone and 1,1,1-trichloropropanone were also identified as volatile reaction products in the sodium hypochlorite reactions. Key words: diacetyl, cleaning chemical, carbonyl reactivity
\end{abstract}

\section{Short Communication}

Diacetyl is a commonly encountered aroma-active compound present in many food systems. Diacetyl has a distinctive buttery aroma and is commonly used to impart flavor to numerous food products such as sour cream, cottage cheese, baked goods, vegetable oil-based spreads, and beverages. Diacetyl is added to these

Received July 2, 2012.

Accepted September 8, 2012.

${ }^{1}$ Corresponding author: sarankin@wisc.edu products either alone or as part of complex flavoring mixtures.

Recent studies have found a direct correlation between exposure to high concentrations of diacetyl and the onset of bronchioloitis obliterans, a debilitating lung disease (Kreiss, 2007; van Rooy et al., 2007). Bronchioloitis obliterans is a rare, irreversible disease in which the formation of granular tissue obstructs the small airways, reducing lung capacity to the degree that a lung transplant may be required. Because of the reported risks that diacetyl may pose, many food companies have altered practices to reduce worker exposure to this chemical or have selected nondiacetyl-based flavorings that may include other vicinal dicarbonyl compounds, such as 2,3-pentanedione.

The US Occupational Health and Safety Administration (OSHA) has provided guidelines to limit worker exposure to diacetyl, including the use of personal respirators, adequate air handling systems, and adequate cleaning practices (OSHA, 2010). Diacetyl and its homologous replacements may be reactive with compounds common to industrial cleaning applications, such as halogen-containing agents, peroxide, or quaternary ammonium compounds.

The different oxidative capacities of these cleaning chemicals and the tendency of carbonyl groups to undergo nucleophilic addition reactions suggest that some of these chemicals may be more prone to react with diacetyl and other vicinal dicarbonyl compounds used as flavorants. It has been reported that $\alpha$-diketones are oxidized by hydrogen peroxide $\left(\mathrm{H}_{2} \mathrm{O}_{2}\right)$ or peroxyacids to the corresponding acid anhydrides (Figures 1 and 2; Cullis et al., 1987) following the epoxide mechanism or the Baeyer-Villiger (BV) reaction (Craig, 1999). The halogen-mediated oxidation of carbonyls to yield first trihalomethyl ketones and finally carboxylic acids (Lieben haloform reaction) is described in Figure 3 (Verter, 1970). The commonly used benzalkonium chloride (BAC) sanitizer is regarded as a surface-active chemical based on the positively charged nitrogen atom. However, its chemical reactivity in this realm has not been reported and it may not react with the carbonyl group. Effectively removing diacetyl from the processing environment and understanding the reactive 
fate of dicarbonyls is a critical component of reducing worker exposure. This work seeks to study the reactivity of diacetyl with 4 commonly used cleaning agents: $\mathrm{H}_{2} \mathrm{O}_{2}$, peroxyacetic acid (PAA), sodium hypochlorite $(\mathrm{NaOCl})$, and $\mathrm{BAC}$ at equimolar ratios and to identify the volatile products of such reactions.

The study was conducted using authentic compounds of diacetyl (99\%), $\mathrm{NaOCl}(10-15 \%)$, PAA (32\%), BAC (95\%), acetic acid (99\%), acetic acid anhydride (99\%), 1,1-dichloro-2-propanone (99\%), and 1,1,1-trichloropro- panone. All reagents were purchased from a single manufacturer (Sigma-Aldrich, St. Louis, MO) except $\mathrm{H}_{2} \mathrm{O}_{2}$ aqueous solution $\left(30 \%\right.$ in $\left.\mathrm{H}_{2} \mathrm{O}\right)$ and the HPLC-grade water used for dilution purposes (both from Fisher Scientific, Chicago, IL). Isopropyl alcohol (99\%) was used as an internal standard (35 mmol; Sigma-Aldrich).

Aqueous solutions containing diacetyl $(50 \mathrm{mmol})$ with equimolar concentrations $(50 \mathrm{mmol})$ of each cleaning chemical in $10-\mathrm{mL}$ glass vials $(23 \times 46 \mathrm{~mm}, 20-\mathrm{mm}$ crimp) were hermetically crimped with an aluminum

1.

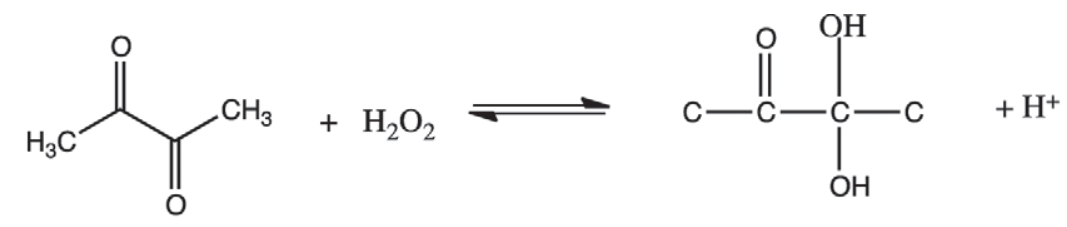

2.

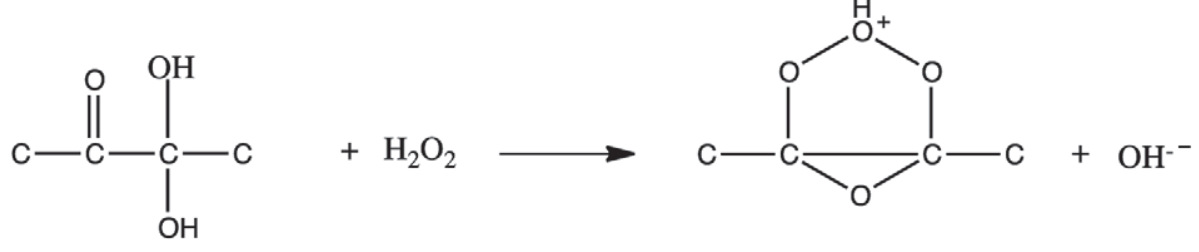

3.

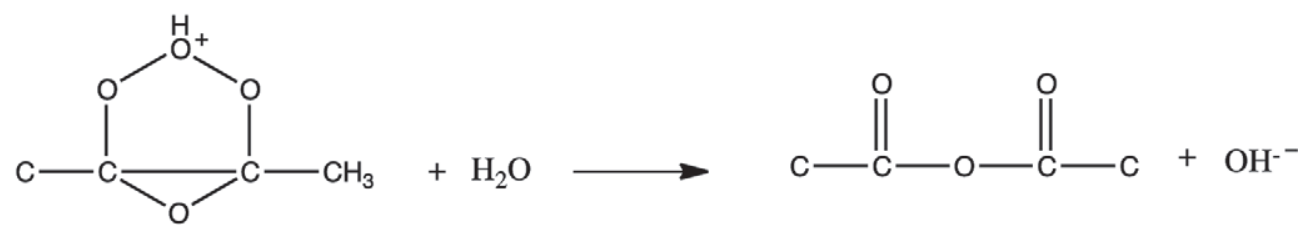

4.

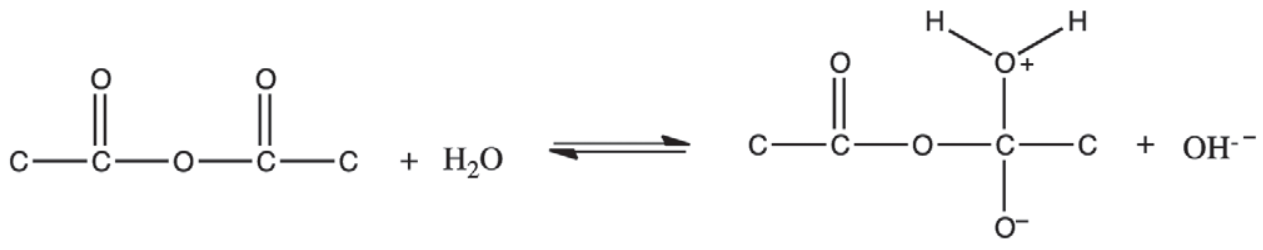

5.

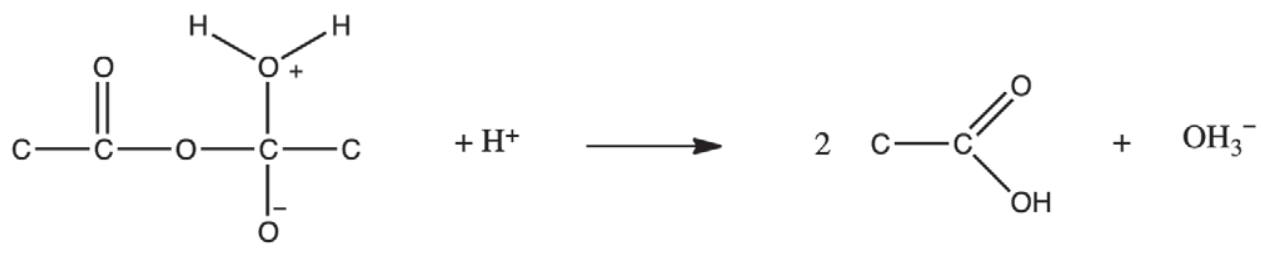

6.

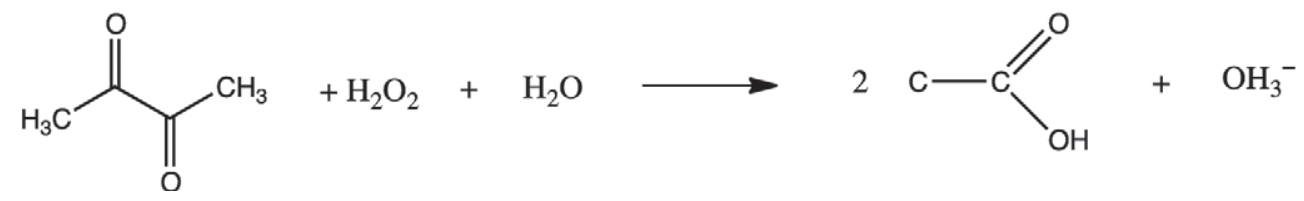

Figure 1. Reactions and stoichiometry of hydrogen peroxide with diacetyl (Frankvoort, 1978). 
1.<smiles>CC(=O)OO[C@@H](C)O[C@H](C)C(C)=O</smiles>

2.

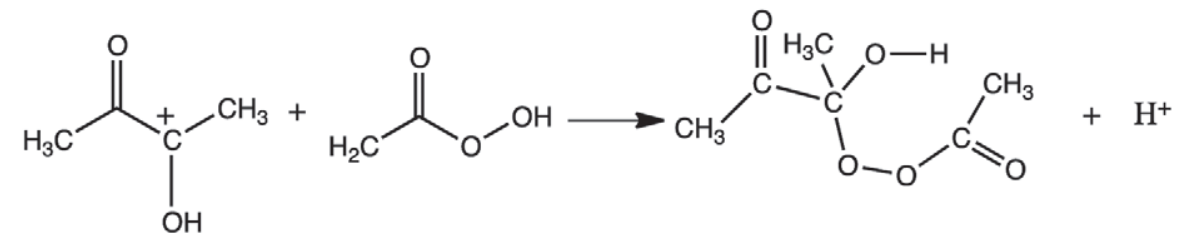

3.

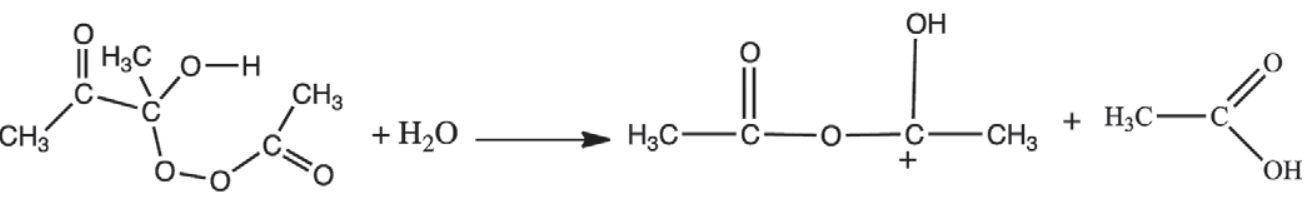

4.<smiles>CC(=O)O[C@@H](C)O</smiles>

5.

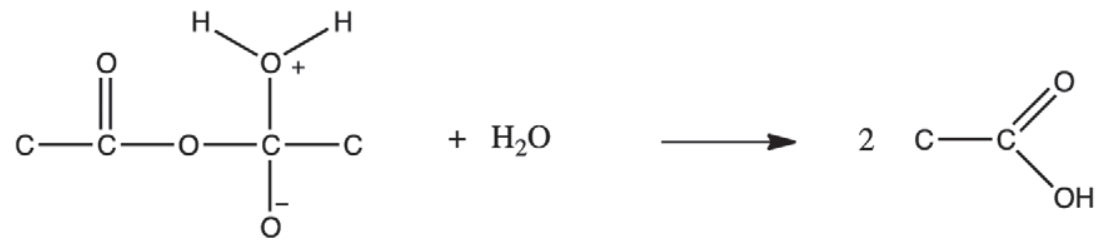

6.

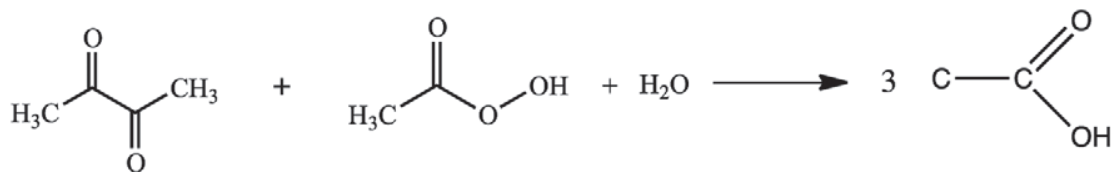

Figure 2. Reactions and stoichiometry of peroxyacetic acid and diacetyl, as proposed by Mora-Diez et al. (2009).

seal capped with butyl-teflon septa. The vials were completely filled to limit the headspace. The reactions were carried out at $40^{\circ} \mathrm{C}$ and sampled every $20 \mathrm{~min}$ for a total of $1.0 \mathrm{~h}$. This temperature was chosen to limit the volatilization of reactants and products during handling. A $1.0-\mu \mathrm{L}$ sample was removed at each timepoint for analysis by GC. Aqueous samples $(1.0 \mu \mathrm{L})$ were injected in the splitless mode using an inverted cup laminar flow liner; triplicate analyses were performed for each treatment. Volatile separation was performed using a gas chromatograph (Agilent 6890N, Agilent
Technologies Inc., Palo Alto, CA) fitted with a fusedsilica capillary column $(\mathrm{RTx}-5 \mathrm{MS}, 30 \mathrm{~m}$ long $\times 0.25$ $\mathrm{mm}$ i.d. $\times 0.5 \mu \mathrm{m}$ film thickness; Restek Corp., Bellefonte, PA) coupled to a mass selective detector (Agilent 5973 MS, Agilent Technologies Inc.). Helium was the carrier gas at a constant flow rate of $1.5 \mathrm{~mL} / \mathrm{min}$. The oven temperature was programmed at a constant temperature of $35^{\circ} \mathrm{C}$ isothermic for $5 \mathrm{~min}$, increased at $20^{\circ} \mathrm{C} / \mathrm{min}$ to $120^{\circ} \mathrm{C}$, and then increased at $40^{\circ} \mathrm{C} / \mathrm{min}$ to $200^{\circ} \mathrm{C}$ and maintained for $2 \mathrm{~min}$. Inlet temperature was $200^{\circ} \mathrm{C}$. Electron impact ionization was used at a 
1.<smiles>CC(=O)C(=O)C[18O]NO[14CH2]C=C[C@@H](C)C(C)=O</smiles>

2.<smiles>CC(=O)C(C)=O</smiles>

3.<smiles>CC(=O)C(C)(O)C([O-])(O)C(C)=O</smiles>

4.

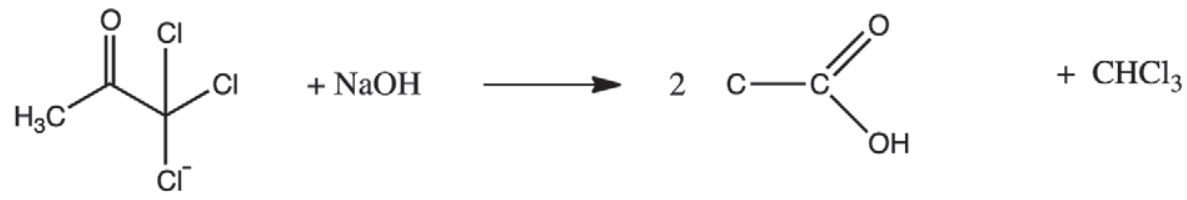

5.

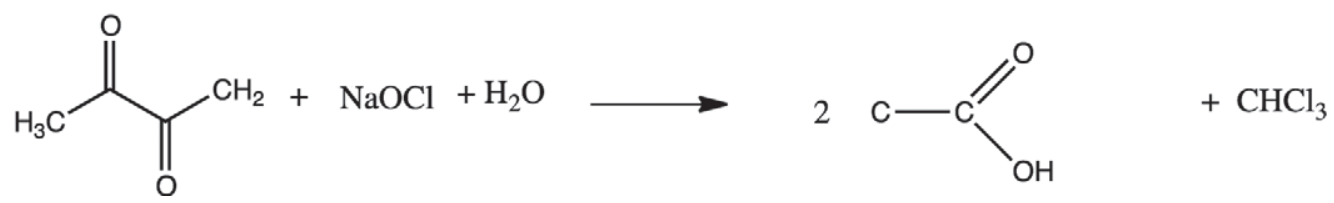

Figure 3. Reactions and stoichiometry of sodium hypochlorite ( $\mathrm{NaOCl}$ ) and diacetyl (adapted from Verter, 1970).

voltage of $70 \mathrm{eV}$. A mass/charge $(\mathrm{m} / z)$ scan range of 29 to $350 \mathrm{amu}$ was collected at 4.44 scans/s. Data analysis was performed using the accompanying computer software (ChemStation Software Rev. D.02.00 SP1, Agilent Technologies Inc.).

Quantitative analysis was based on the linear response range of a 5 -point series of internal (for diacetyl from 0.2 to $100 \mathrm{mmol}$ ) and external calibration curves with their respective ranges: acetic acid (5-500 mmol), acetic acid anhydride $(0.2-10 \mathrm{mmol})$, 1,1-dichloro2-propanone (0.1-2.0 mmol), and 1,1,1-trichloropropanone $(0.1-1.5 \mathrm{mmol})$. All analysis were performed in triplicate $\left(\mathrm{R}^{2}>0.99\right)$, and ANOVA with Tukey pairwise comparisons were done where appropriate with $\alpha<$ 0.05 . Because diacetyl was the only compound present across all treatments, data from other compounds were not statistically analyzed.

Hydrogen peroxide, noted as a nucleophilic reagent, is capable of effecting substitution reactions (Swern, 1949) and epoxidation of alkenes. However, $\mathrm{H}_{2} \mathrm{O}_{2}$ is a weak electrophile whose activity is enhanced in combination with transition metals, including oxides (Mimoun, 1985) and Lewis acids (Olah and Ramaiah, 1993). Acetic acid was identified as the main product of this reaction (Table 1). According to Frankvoort (1978), the stoichiometry of this reaction involves $1 \mathrm{~mol}$ of diacetyl reacting with $1 \mathrm{~mol}$ of $\mathrm{H}_{2} \mathrm{O}_{2}$ to yield 2 moles of acetic acid (Figure 1). Table 1 shows a mass balance supporting this stoichiometry. The initial diacetyl concentration was $50 \mathrm{mmol}$; subsequently, at $1 \mathrm{~min}$, 
Table 1. Average concentrations (mmol) of diacetyl ${ }^{1}$ and related volatiles in cleaning chemical reactions at 1, 20, 40, and 60 min

\begin{tabular}{|c|c|c|c|c|c|}
\hline $\begin{array}{l}\text { Reaction time/ } \\
\text { cleaning agent }^{2}\end{array}$ & Diacetyl & $\begin{array}{l}\text { Acetic } \\
\text { acid }\end{array}$ & $\begin{array}{l}\text { Acetic acid } \\
\text { anhydride }\end{array}$ & $\begin{array}{l}\text { 1,1-Dichloro-2- } \\
\text { propanone }\end{array}$ & $\begin{array}{c}1,1,1- \\
\text { Trichloropropanone }\end{array}$ \\
\hline $\begin{array}{l}0 \min \\
(\mathrm{pH}=5.0)\end{array}$ & $50(0)$ & & & & \\
\hline $\begin{array}{l}40 \mathrm{~min} \\
\mathrm{H}_{2} \mathrm{O}_{2}(\mathrm{pH}=3.9) \\
\mathrm{PAA}(\mathrm{pH}=3.1) \\
\mathrm{NaOCl}(\mathrm{pH}=4.6) \\
\mathrm{BAC}(\mathrm{pH}=5.8)\end{array}$ & $\begin{array}{l}38(1.7)^{\mathrm{b}} \\
2.9(0.2)^{\mathrm{d}} \\
13(2.6)^{\mathrm{c}} \\
50(1.5)^{\mathrm{a}}\end{array}$ & $\begin{array}{r}19(0.3) \\
110(5.8) \\
76(8.5)\end{array}$ & & $0.9(0.2)$ & $0.6(0.0)$ \\
\hline
\end{tabular}

\footnotetext{
${ }^{\mathrm{a}-\mathrm{d}}$ Means with different lowercase letters within a time period indicate significant $(P<0.05)$ differences in diacetyl concentration. ${ }^{1}$ Mean concentrations of triplicate measurements (SD in parentheses).

${ }^{2} \mathrm{H}_{2} \mathrm{O}_{2}=$ hydrogen peroxide; PAA $=$ peroxyacetic acid; $\mathrm{NaOCl}=$ sodium hypochlorite; $\mathrm{BAC}=$ benzalkonium chloride.
}

8 mmol of diacetyl reacted with $\mathrm{H}_{2} \mathrm{O}_{2}$ to produce 16 mmol of acetic acid. At 20 min, diacetyl levels remained stable, as did acetic acid levels. Diacetyl concentration decreased to $38 \mathrm{mmol}$ and acetic acid to $19 \mathrm{mmol}$ at 40 min. After $1 \mathrm{~h}$ of reaction, $26 \%$ of the total concentration of diacetyl reacted with $\mathrm{H}_{2} \mathrm{O}_{2}$, yielding $21 \mathrm{mmol}$ of acetic acid.

The second reaction of this study was conducted with diacetyl and PAA; PAA typically acts as an electrophilic compound capable of reacting with many functional groups, including ketones. Over the course of this oxidative reaction, acetic acid was identified as a final product and acetic acid anhydride as an intermediate (Table 1). Diacetyl levels monitored over time showed reductions to $23 \mathrm{mmol}$ ( $1 \mathrm{~min}$ ), $2.8 \mathrm{mmol}$ (20 min), 2.9 mmol (40 min), and $2.7 \mathrm{mmol}$ (60 min). A mechanism of reaction of diacetyl with PAA is suggested in Figure 2 based on the stoichiometry of the reaction of a ketone with PAA proposed by Mora-Diez et al. (2009), wherein 1 mol of diacetyl reacts with $1 \mathrm{~mol}$ of PAA to produce 3 mol of acetic acid. After $60 \mathrm{~min}$, this resulted in a final acetic acid concentration of $115 \mathrm{mmol}$.

Several authors have described the reactions of peroxy compounds and ketones. Holleman (1904) proposed the production of acetic acid as the final product in the reaction of $\mathrm{H}_{2} \mathrm{O}_{2}$ with diacetyl. Weitz and Scheffer (1921) described a reaction of diacetyl and $\mathrm{H}_{2} \mathrm{O}_{2}$ involving the formation of an unstable diperoxide followed by a ring-shaped superoxide that results in acetic acid anhydride. The latter is hydrolyzed into acetic acid in aqueous solution. Other publications support the theory that acetic acid anhydride is an intermediate product of the oxidation of diketones with hydrogen peroxide in aqueous solution, requiring water to complete the hydrolysis of the reaction (Barnes and Lewis, 1936; Leffler and Petropoulos, 1957). Potential reaction mechanisms include BV and the epoxide mechanism. The first mechanism of oxidation involves the formation of esters or lactones under acidic or alkaline condition in 2 steps (Craig, 1999). The first step is the carbonyl addition of a peroxyacid to a ketone, resulting in a product known as a Criegee intermediate, which is a tetrahedral adduct. The second is the migration of the alkyl or aryl group from the ketone moiety to the nearest peracid oxygen atom; simultaneously, dissociation of the O-O bond occurs (Doering and Dorfman, 1953). According to Criegee (1948), the reaction results in a nucleophilic attack of peracid onto the electron-poor carbonyl carbon followed by a migration of an electron pair with the release of the carboxylate anion. This rearrangement has been described as an intramolecular rearrangement involving electrophilic oxygen (Wilt and Danielzadeh, 1958). In contrast, other researchers described base-catalyzed epoxidation as a mechanism of reaction between epoxy compounds and $\alpha$-diketones (Cullis et al., 1987). The direction of the cleavage differs from that observed in a BV reaction. According to Cullis et al. (1987), an $\alpha$-diketone reacting with 
peracetic or $\mathrm{H}_{2} \mathrm{O}_{2}$ following the $\mathrm{BV}$ mechanism results in an acyl or alkyl group migration without formation of an $\alpha$-ketoester. Those authors concluded that the mechanism of peracid oxidation of $\alpha$-diketone follows an epoxide mechanism.

Sodium hypochlorite has a strong capacity to oxidize functional groups, including alcohols (Procter, 1991), aldehydes (Abramovici et al., 1985), electron-deficient alkenes (Marmor, 1963), and amines (Lee and Freedman, 1976). Neiswender et al. (1960) reported that diketones might be oxidized with $\mathrm{NaOCl}$ to give their corresponding diacids. Besides acetic acid, which was identified as the primary final product, low levels of 1,1-dichloro-2-propanone and 1,1,1-trichloropropanone were positively identified (Table 1). Diacetyl levels decreased over time: $42 \mathrm{mmol}$ (1 min), $24 \mathrm{mmol}$ (20 min), $13 \mathrm{mmol}$ (40 min), and $12 \mathrm{mmol}$ (60 min). Based on the stoichiometry of reactions between ketones and $\mathrm{NaOCl}$ suggested by Patai and Zabicky (1970), $1 \mathrm{mmol}$ of diacetyl produced 2 mol of acetic acid (Figure 3).

Acetic acid concentration increased over time, yielding a final concentration of $92 \mathrm{mmol}$. In addition, at $1 \mathrm{~min}, 1.2 \mathrm{mmol}$ of 1,1-dichloro-2-propanone and 1.1 mmol of 1,1,1-trichloropropanone were quantified.

Ketones undergo oxidative reactions thought to follow the Lieben haloform mechanism (Hashmi and Ayaz, 1964). According to Littler (1962), ketone oxidation with $\mathrm{NaOCl}$ proceeds by halogenation at the $\alpha$-carbon, with enolization as a first step (the rate-controlling step). The $\alpha$-haloketones are more reactive than their precursors, concluding with a rapid halogenation to the trihalo form. Trihalomethyl ketones are susceptible to alkaline cleavage and they are subsequently cleaved to carboxylic acids (Carey and Sundberg, 2007). However, a detailed mechanism of halogenation in $\alpha$-diketones has not been published to our knowledge. The formation of 1,1,1-trichloropropanone and 1,1-dichloro-2-propanone remains unclear. 1,1,1-Trichloropropanone has been identified as a chlorination byproduct in finished drinking water supplies (Suffet et al., 1976). 1,1,1-Trichloropropanone and 1,1-dichloro-2-propanone are linked to liver, forestomach, and kidney toxicity when ingested by rats at $80 \mathrm{mg} / \mathrm{kg}$ per day for 90 consecutive days (Daniel et al., 1991).

Benzalkonium chloride is defined as a surface-active agent derived from the reaction of tertiary amines and quaternizing agent (benzyl chloride), which exhibits detergent-type action and germicidal and mold-reducing properties (Beyth et al., 2006). The mechanism of action of BAC is similar to that of cationic surfactants, including reduction of surface tension, attraction to negatively charged entities (proteins and bacteria), formation of ionic aggregates, and changes in conduc- tivity. Diacetyl concentrations remained constant and the formation of volatile reaction products was not observed in reactions with $\mathrm{BAC}$.

All treatments at $1,20,40$, and 60 min were statistically different (Table 1) except for diacetyl treated with $\mathrm{H}_{2} \mathrm{O}_{2}$ and $\mathrm{NaOCl}$ at 1 min, where no significant difference was found $(P<0.05)$. The $\mathrm{pH}$ of each of the treatments also changed based on the chemistry of the added cleaning chemical and the resulting reaction products, namely acetic acid (Table 1). Although $\mathrm{pH}$ changes could have been attenuated with buffers, this approach was not taken to be more reflective of an actual system, and $\mathrm{pH}$ changes were documented over the course of the reactions.

Besides its efficacy in reacting with diacetyl, PAA has been reported to have bactericidal, antimicrobial, fungicidal, and antiviral characteristics, even in the presence of heterogeneous organic matter, and it has been promoted as a potential chlorine replacement (McDonnell and Russell, 1999). The attributes of PAA are the ease of implementing treatment, low dependence on $\mathrm{pH}$, short contact time needed, and effectiveness for primary and secondary effluents (Klaas et al., 2002; Kitis, 2004). The acute toxicity of PAA is low but it has been noted to cause irritation to the eyes, skin, and mucous membranes (Hickman, 2002).

Although identified as the main product of reactions of diacetyl with PAA, NaOCl, and $\mathrm{H}_{2} \mathrm{O}_{2}$, acetic acid has not been linked to bronchiolitis obliterans or other serious diseases. However, acetic acid may cause sensitization by skin contact and can cause irritation of the mouth, nose, and throat; coughing; and shortness of breath. According to Ernstgard et al. (2006), vapors of acetic acid may cause erosion on teeth in workers exposed for 7 to $12 \mathrm{yr}$ at $80 \mu \mathrm{g} / \mathrm{g}$. Exposure limits [i.e., OSHA permissible exposure limit and lethal concentration 50 (LC50)] for diacetyl have not been established, whereas the OSHA permissible exposure limit of acetic acid is $10 \mu \mathrm{g} / \mathrm{g}$ time-weighted average for an 8-h work shift.

This work examined the reactivity of diacetyl with common industrial cleaning and sanitizing chemicals and identified the volatile reaction products. The most efficient cleaning chemical was PAA, which showed removal of $53 \%$ of the total concentration of diacetyl at $1 \mathrm{~min}$ and a residual diacetyl concentration of $5.7 \%$ at 20 min. Hydrogen peroxide and $\mathrm{NaOCl}$ showed weaker efficacy in reacting with diacetyl, whereas BAC did not react with diacetyl under the conditions of this study. Effectively removing diacetyl from the processing environment and understanding the reactive fate of these dicarbonyls is a critical component of reducing worker exposure. Additional work may involve the understand- 
ing of reactivity with other nondiacetyl base flavorants and high-priority flavor components and the evaluation of nonvolatile intermediates and end-products.

\section{REFERENCES}

Abramovici, S., R. Neumann, and Y. Sasson. 1985. Sodium hypochlorite as oxidant in phase transfer catalytic systems: Part II. Oxidation of aromatic alcohols. J. Mol. Catal. Chem. 29:299-303.

Barnes, R. P., and R. E. Lewis. 1936. The action of ethylhydroperoxide on alpha diketones-Mechanism. J. Am. Chem. Soc. 58:947-948.

Beyth, N., I. Yudovin-Farber, R. Bahir, A. J. Domb, and E. I. Weiss. 2006. Antibacterial activity of dental composites containing quaternary ammonium polyethylenimine nanoparticles against Streptococcus mutans. Biomaterials 27:3995-4002.

Carey, F. A., and F. Sundberg. 2007. Oxidations. Pages 1063-1151 in Advanced Organic Chemistry: Reactions and Synthesis. Springer Science+Business Media LLC, New York, NY.

Craig, J. W. 1999. Activation of hydrogen peroxide using inorganic and organic species. Pages 37-77 in Applications of Hydrogen Peroxide and Derivatives. J. H. Clark, ed. Royal Society of Chemistry, Cambridge, UK.

Criegee, R. 1948. Die Umlagerung der Dekalin-peroxydester als Folge von kationischem Sauerstoff. Ann. Chem. 560:127-135.

Cullis, P. M., J. R. P. Arnold, M. Clarke, R. Howell, M. deMira, M. Naylor, and D. Nicholls. 1987. On the mechanism of peracid oxidation of $\alpha$-diketones to acid anhydrides: $\mathrm{An}{ }^{17} \mathrm{O}$ and ${ }^{18} \mathrm{O}$ isotope study. J. Chem. Soc. Chem. Commun. 14:1088-1089.

Daniel, F. B., G. R. Olson, and J. A. Strober. 1991. Induction of gastrointestinal tract nuclear anomalies in $\mathrm{B} 6 \mathrm{C} 3 \mathrm{~F} 1$ mice by 3-chloro4-(dichloromethyl)-5-hydroxy-2(5H)-furanone and 3,4-(dichloro)5 -hydroxy-2(5H)-furanone, mutagenic by-products of chlorine disinfection. Environ. Mol. Mutagen. 17:32-39.

Doering, W. V., and E. Dorfman. 1953. Mechanism of the peracid ketone-ester conversion. Analysis of organic compounds for oxygen-18. J. Am. Chem. Soc. 75:5595-5598.

Ernstgard, L., A. Iregren, B. Sjogren, and G. Johanson. 2006. Acute effects of exposure to vapours of acetic acid in humans. Toxicol. Lett. 165:22-30.

Frankvoort, W. 1978. The reaction between diacetyl and hydrogen peroxide: Its mechanism and kinetic constants. Thermochim. Acta 25:35-49.

Hashmi, M. H., and A. A. Ayaz. 1964. Determination of methyl ketones and acetaldehyde by titration with hypobromite using Bordeaux indicator. Anal. Chem. 36:384-386.

Hickman, W. S. 2002. Peracetic acid and its use in fibre bleaching. Pages 13-27 in Review of Progress in Coloration and Related Topics. Vol. 32. Society of Dyers and Colourists (SDC), Oxford, UK.

Holleman, M. A. F. 1904. Notice sur l'action de l'eau oxygenee sur les acides $\alpha$-cetoniques et sur les dicetones 1.2. Recl. Trav. Chim. Pays-Bas Belg. 23:169-172.

Kitis, M. 2004. Disinfection of wastewater with peracetic acid: A review. Environ. Int. 30:47-55.
Klaas, M. R., K. Steffens, and N. Patett. 2002. Biocatalytic peroxy acid formation for disinfection. J. Mol. Catal. B Enzym. 19:499505

Kreiss, K. 2007. Flavoring-related bronchiolitis obliterans. Curr. Opin. Allergy Clin. Immunol. 7:162-167.

Lee, G. A., and H. H. Freedman. 1976. Phase transfer catalyzed oxidations of alcohols and amines by aqueous hypochlorite. Tetrahedron Lett. 17:1641-1644.

Leffler, J. E., and C. C. Petropoulos. 1957. 4-Methoxy-3',5'dinitrobenzoyl peroxide. J. Am. Chem. Soc. 79:3068-3071.

Littler, J. S. 1962. The mechanisms of oxidation of cyclohexanone under acid conditions. Part II. One-electron oxidants. J. Chem. Soc. 69:832-837.

Marmor, S. 1963. The epoxidation of certain $\alpha, \beta$-unsaturated ketones with sodium hypochlorite. J. Org. Chem. 28:250-251.

McDonnell, G., and A. D. Russell. 1999. Antiseptics and disinfectants: Activity, action, and resistance. Clin. Microbiol. Rev. 12:147-179.

Mimoun, H. 1985. Metal Complexes in Oxidation. Elsevier, New York, NY.

Mora-Diez, N., S. Keller, and J. R. Alvarez-Idaboy. 2009. The BaeyerVilliger reaction: Solvent effects on reaction mechanisms. Org. Biomol. Chem. 7:3682-3690.

Neiswender, D. D., Jr., W. B. Moniz, and J. A. Dixon. 1960. The oxidation of methylene and methyl groups by sodium hypochlorite. J. Am. Chem. Soc. 82:2876-2878.

Olah, G. A., and P. Ramaiah. 1993. Oxygenation of bicyclo[2.2.1]heptane and bicylo[2.2.2]octane with nitronium tetrafluoroborate. J. Org. Chem. 58:4639-4641.

OSHA (Occupational Health and Safety Administration). 2010. Occupational exposure to flavoring substances: Health effects and hazard control. Safety and Health Information Bulletin. Accessed Apr. 14, 2012. http://www.osha.gov/dts/shib/shib10142010.html.

Patai, S. E., and J. Z. Zabicky. 1970. The Chemistry of the Carbonyl Group. John Wiley \& Sons Ltd., New York, NY.

Procter, G. 1991. Oxidation adjacent to oxygen of alcohols by other methods. Pages 305-328 in Comprehensive Organic Synthesis: Selectivity, Strategy \& Efficiency in Modern Organic Chemistry. Vol. 7: Oxidation. S. V. Ley, ed. Elsevier Ltd., Kidlington, Oxford, UK.

Suffet, I. H., L. Brenner, and B. Silver. 1976. Identification of 1,1,1-trichloroacetone (1,1,1-trichloropropanone) in two drinking waters: A known precursor in haloform reaction. Environ. Sci. Technol. 10:1273-1275.

Swern, D. 1949. Organic peracids. Chem. Rev. 45:1-68.

van Rooy, F. G., J. M. Rooyackers, M. Prokop, R. Houba, L. A. Smit, and D. J. Heederik. 2007. Bronchiolitis obliterans syndrome in chemical workers producing diacetyl for food flavorings. Am. J. Respir. Crit. Care Med. 176:498-504.

Verter, H. S. 1970. Oxidation of aldehydes and ketones. Pages 71-156 in The Chemistry of the Carbonyl Group. Vol. 2. J. S. E. Patai and J. Z. Zabicky, ed. John Wiley \& Sons Ltd., New York, NY.

Weitz, E., and A. Scheffer. 1921. Action of alkaline hydrogen peroxide on unsaturated compounds. Chem. Ber. 54:2327-2344.

Wilt, J., and A. Danielzadeh. 1958. The neopentyl and neophyl systems in peracid oxidation of ketones. J. Org. Chem. 23:920-921. 